\title{
EFFICACY OF CARBOXYMETHYLCELLULOSE VS POLYETHYLENE GLYCOL ARTIFICIAL TEAR FORMULATION FOR DRY EYE
}

\author{
Archana Vilas Manekar1, Ruchita Pradeep Rathi², Neha Chandrashekar Yerawar ${ }^{3}$ \\ ${ }^{1}$ Associate Professor, Department of Ophthalmology, Dr. PDM Medical College, Amravati, Maharashtra, India. \\ 2Junior Resident, Department of Ophthalmology, Dr. PDM Medical College, Amravati, Maharashtra, India. \\ 3Junior Resident, Department of Ophthalmology, Dr. PDM Medical College, Amravati, Maharashtra, India.
}

\section{ABSTRACT}

\section{BACKGROUND}

Dry eye is a multifactorial disease of the tears and ocular surface that results in symptoms of discomfort, visual disturbance and tear film instability with potential damage to the ocular surface. It is accompanied by increased osmolarity of the tear film and inflammation of the ocular surface. Dry eye is one of the most common causes of ocular morbidity in patients presenting to an ophthalmology outpatient department. Artificial tears are aqueous solutions containing polymers that determine their viscosity, retention time and adhesion to the ocular surface. In mild-to-moderate cases, they are the mainstay of treatment. Artificial tears act by replenishing the deficient aqueous layer of the tear film and diluting the inflammatory cytokines.

Hence, in this study we are comparing the efficacy of carboxymethylcellulose with polyethylene glycol eye drops through Schirmer's test and Tear Break-Up time.

\section{MATERIALS AND METHODS}

A prospective evaluation of cases presenting with symptoms of dry eye from March 2015 to April 2017 was done in tertiary health care. Patients with dry eye were identified with the help of slit lamp examination, Schirmer's test (ST) and Tear Break-Up Time (TBUT). One group was instilled with one drop of carboxymethylcellulose (CMC 0.5\%), while the second group was instilled with one drop of polyethylene glycol (PEG 400/PG). Both groups were prescribed their respective eye drops at a dose of three times a day and ST and TBUT were performed on day 0,7 and 30.

\section{RESULTS}

Overall, 100 patients were included in the study. Demographic data and baseline characteristics were comparable among the groups. Group 2 had significant improvement in mean change in TBUT (week 0- $\mathrm{P}=0.001$; week $1-\mathrm{P}=0.001$; and week 4- $\mathrm{P}=$ 0.001 ), and in ST (week 0- $\mathrm{P}=0.02$; week $1-\mathrm{P}=0.04$; and week 4- $\mathrm{P}=0.03$ ) compared to Group 1 at all follow-ups.

\section{CONCLUSION}

Polyethylene glycol is better tear substitute than carboxymethylcellulose in improving objective component of dry eye, while improvement in subjective component is same with PEG 400/ PG and CMC 0.5\%.

\section{KEY WORDS}

Artificial Tear, Carboxymethylcellulose, Dry Eye, Polyethylene Glycol.

HOW TO CITE THIS ARTICLE: Manekar AV, Rathi RP, Yerawar NC. Efficacy of carboxymethylcellulose vs polyethylene glycol artificial tear formulation for dry eye. J. Evolution Med. Dent. Sci. 2018;7(31):3541-3543, DOI: 10.14260/jemds/2018/795

\section{BACKGROUND}

In 1995, the National Eye Institute defined dry eye as 'a disorder of the tear film due to tear deficiency or excessive evaporation, which causes damage to interpalpebral ocular surface and is associated with symptoms of ocular discomfort.[1]

In 2007, Dry Eye Workshop improvised the definition as follows- 'Dry eye is a multifactorial disease of the tears and ocular surface that results in symptoms of discomfort, visual disturbance and tear film instability with potential damage to the ocular surface.[2] It is accompanied by increased osmolarity of the tear film and inflammation of the ocular surface.'[2]

'Financial or Other Competing Interest': None.

Submission 11-06-2018, Peer Review 12-07-2018,

Acceptance 19-07-2018, Published 30-07-2018.

Corresponding Author:

Dr. Ruchita Pradeep Rathi,

Room No. 18, PG Hostel,

Dr. PDM Medical College, Shivaji Nagar,

Panchvati, Amravati-444603, Maharashtra, India.

E-mail: ruchitarathi1981@gmail.com

DOI: $10.14260 /$ jemds $/ 2018 / 795$

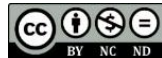

Dry eye is one of the most common causes of ocular morbidity in patients presenting to an Ophthalmology Outpatient Department. The Beaver Dam Study demonstrated an incidence of dry eye of 13.33 percent that significantly correlated with patient's age. With such high rate, the main stay of treatment is artificial tears. ${ }^{[3]}$ Dry eye was apparently higher in women $(14.7 \%)$ than men $(11.7 \%) .{ }^{[4]}$

Artificial tears are aqueous solutions containing polymers that determine their viscosity, retention time and adhesion to the ocular surface. Various polymers currently in use include cellulose derivatives (e.g. hydroxypropyl methylcellulose [HPMC], carboxymethylcellulose [CMC]), polyethylene glycol, polyvinyl derivatives (e.g. polyvinyl alcohol), chondroitin sulfate and sodium hyaluronate.[2,5] In mild-to-moderate cases, they are the mainstay of treatment. Artificial tears act by replenishing the deficient aqueous layer of the tear film and diluting the inflammatory cytokines.[2,5]

The ideal artificial tears should be preservative-free; contains potassium, bicarbonate and other electrolytes and have polymeric system to increase its retention time.[6-8] Physical properties should include a neutral to slightly alkaline pH. Osmolarities of artificial tears have been measured to range from about 181 to $354 \mathrm{mOsm} / \mathrm{L}$. [9] 
In this study, we are comparing the efficacy of carboxymethylcellulose with polyethylene glycol eye drops through Schirmer's test and tear break-up time.

\section{MATERIALS AND METHODS}

A non-randomised controlled trial study was conducted on 100 patients to compare the efficacy of CMC $0.5 \%$ and PEG 400/ PG eye drops in treatment of mild-to-moderate dry eyes in tertiary health care centre for a period of 25 months. The patients satisfying inclusion criteria were followed for a period of 25 months. Assessment of outcome was done on the basis of slit lamp examination and TBUT and ST and subjective improvement. Ethical clearance for the study was taken from the local Institutional Review Board/ Ethical Committee and informed consent was taken from the patients.

\section{Justification of Sample Size}

All patients enrolled for eye treatment in Maharashtra from March 2015 to April 2017 was done in tertiary health care were taken up for the study. A total of 100 patients were registered in Maharashtra between March 2015 and April 2017 in the assessment of outcome was done on the basis of slit lamp examination and TBUT and ST and subjective improvement. Ethical clearance for the study was taken from the local Institutional Review Board/ Ethical Committee and informed consent was taken from the patients.

Data was collected through patient interviews using questionnaires. Enrolled patients were interviewed. Interviews were conducted in local language. Initial pilot testing of the questionnaire was already done.

\section{Schirmer's Test}

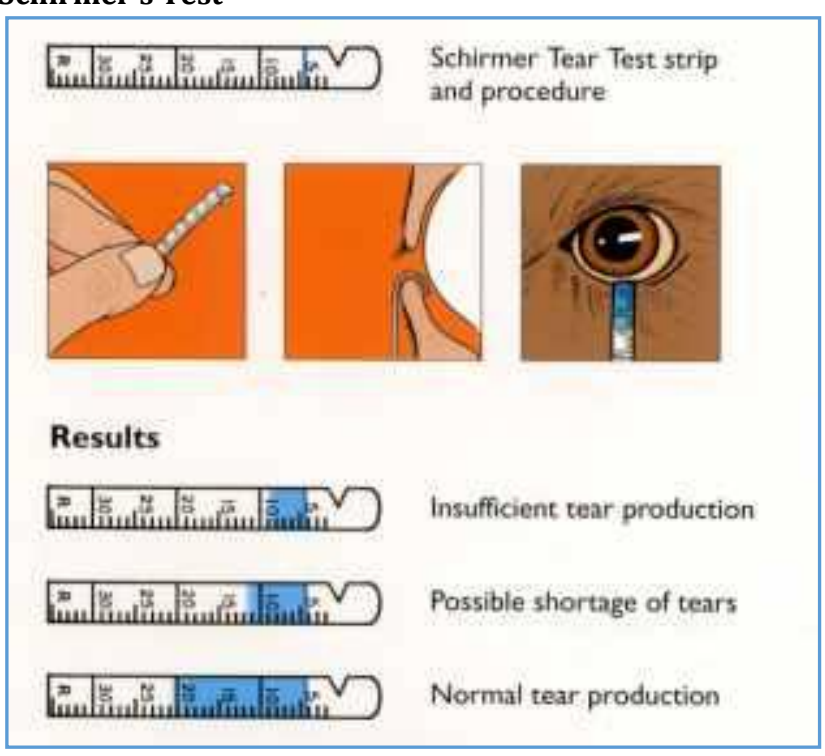

\section{Interpretation}

- Normal: > $15 \mathrm{~mm}$.

- Mild-to-moderate Keratoconjunctivitis sicca (KCS): 5 - 10 $\mathrm{mm}$.

- $\quad$ Severe KCS: $<5 \mathrm{~mm}$.

\begin{tabular}{|c|c|}
\hline Values & Interpretation \\
\hline Less than 10 & Abnormal \\
\hline Between 5-9 & Borderline Dry Eye \\
\hline Less than 5 & Severe Dry Eye \\
\hline \multicolumn{2}{|c|}{ Tear Break-Up Time Test } \\
\hline
\end{tabular}

\section{Inclusion Criteria}

Patients above 20 yrs. of age presenting with symptoms of dry eye (mild-to-moderate) in the tertiary health care system.

\section{Exclusion Criteria}

- $\quad$ Already on treatment for dry eye.

- Cases in whom dry eye was secondary to some ocular or systemic disease.

- $\quad$ Cases with severe dry eye.

- Post-operative cases and patients with any concurrent disease or condition that could have complicated or interfered with the administration or evaluation of the study drug.

For the purpose of the study, cases were divided into two groups. Group 1 cases were prescribed with CMC 0.5\% eye drops three times a day and Group 2 cases were prescribed with PEG 400/ PG eye drop three times a day.

Details of demographic data such as age and sex were recorded. Parameters such as Tear Film Break-Up Time (TBUT), Schirmer's Test (ST) and slit-lamp examination findings were recorded at day 0 (before start of treatment), week 1 and week 4. Comparative analysis was done among different groups for improvement in TBUT and ST at each follow-up. Subjective improvement was also noted.

\section{Statistical Method}

The efficacy variables included TBUT and ST. All variables were evaluated at days 0,1 week and 4 weeks. The unpaired t-test was used to compare treatment group differences in demographic characteristics.

\section{RESULTS}

One hundred patients were included in the study. Group 1 (CMC 0.5\%) and Group 2 (PEG 400/PG) included 50 cases, each. Group 1 included 28 females and 22 males and Group 2 included 24 females and 26 males. The mean age in Group 1 was 47.3 and that in Group 2 was 52.1. Demographic data were similar across treatment. The two groups were comparable in their baseline characteristics that included mean TBUT $(p=0.001)$ and the mean scores for ST $(p=0.02)$ Cases were then divided into mild and moderate depending on their TBUT and ST scores.

$\begin{array}{lccc}\text { Mean } & \text { Group 1 } & \text { Group 2 } & \text { p value } \\ \text { Age } & 47.3 \pm 3.71 & 52.1 \pm 6.33 & \\ \text { Female to male } & 1.22: 1 & 0.92: 1 & \\ \text { TBUT } & 8.01 \pm 0.42 & 7.02 \pm 0.60 & 0.001 \\ \text { ST } & 20.80 \pm 2.18 & 19.42 \pm 2.13 & 0.02 \\ & & \\ \text { Group 1: carboxymethylcellulose 0.5\%, Group 2: polyethylene } \\ \text { glycol400/propylene glycol, TBUT: tear film break up time, ST: schirmer test }\end{array}$

\section{Tear Break-Up Time}

Mean TBUT in Group 1 was $8.21 \pm 0.294$ (SD) at week 1 and $8.588 \pm 0.273$ (SD) at week 4. Mean TBUT in Group 2 was $7.55 \pm 0.281(\mathrm{SD})$ at week 1 and $8.166 \pm 0.232$ (SD) at week 4 . Patients in Group 2 had a significant increase in mean TBUT than those in Group 1 at week $1(p=0.001)$ and at week 4 (0.001). 


\section{Schirmer's Test}

Mean ST in Group 1 was $21.18 \pm 2.229$ (SD) at week 1 and $21.66 \pm 2.096$ (SD) at week 4. Mean ST in Group 2 was 19.80 \pm 2.139 (SD) at week 1 and $20.22 \pm 2.667$ (SD) at week 4 . Patients in Group 2 exhibited significant improvement in ST than Group 1 at week $1(p=0.04)$ and week $4(p=0.03)$.

\section{DISCUSSION}

Dry eye is characterised by tear film instability and ocular surface damage. The primary objective of this randomised, double-blind clinical study was to evaluate mean change from baseline to week 4 in TBUT and ST, as a sign of dry eye, in patients receiving PEG-containing or CMC-containing eye drops. In clinical studies, the daily use of PEG/ PG for 28 days or more in patients with dry eye has been consistently associated with significant decrease in conjunctival and/or corneal staining, increase in TBUT and ST, in patient-assessed parameters (Drop comfort, ocular comfort and dry eye symptoms). Patients showed improvements with PEG eye drops better than that with CMC eye drops. These results indicate that ocular surface damage may be ameliorated to a greater degree with this PEG restorative eye drops formula than with CMC eye drops after 4 weeks of treatment. Because dry eye is a multifactorial disease, a treatment difference observed in a single study parameter may not translate to a clinically meaningful difference in the management of dry eye symptoms. Both treatments were well tolerated.

The result of our study corroborates with those of previous studies. Thus, it can be concluded that PEG 400/ PG can lead to early and sustained relief in both objective and subjective parameters compared to CMC $0.5 \%$ tear substitute.

\section{CONCLUSION}

To conclude, both artificial tears such as PEG 400/ PG and CMC $0.5 \%$ are equally effective in improving the subjective component of dry eye, while the improvement in objective parameters is more consistent with PEG 400/ PG tear substitutes.

\section{REFERENCES}

[1] Lemp MA. Report of the National Eye Institute /Industry workshop on clinical trials in dry eye. CLAO J 1995;21(4):221-32.

[2] The epidemiology of dry eye disease: report of the Epidemiology Subcommittee of the International Dry Eye Work Shop (2007). Ocul Surf 2007;5(2):93-107.

[3] Moss SE, Klein R, Klein BE. Incidence of dry eye in older population. Arch Ophthalmol 2004;122(3):36973.

[4] Schein OD, Munoz B, Tielsch JM, et al. Prevalence of dry eye among elderly. Am J Ophthalmol 1997;124(6):723-8.

[5] Moshirfar M, Pierson K, Hanamaikai K, et al. Artificial tears potpourri: a literature review. Clin Ophthalmol 2014;8:1419-33.

[6] Gilbard JP, Rossi SR, Heyda KG. Ophthalmic solutions, the ocular surface, and a unique therapeutic artificial tear formulation. Am J Ophthalmol 1989;107(4):34855.

[7] Ubels JL, McCartney MD, Lantz WK, et al. Effects of preservative-free artificial tear solutions on corneal epithelial structure and function. Arch Ophthalmol 1995;113(3):371-8.

[8] Green K, MacKeen DL, Slagle T, et al. Tear potassium contributes to maintenance of corneal thickness. Ophthalmic Res 1992;24(2):99-102.

[9] Perrigin DM, Morgan A, Quintero S, et al. Comparison of osmolarity values of selected ocular lubricants. ARVO 2004;45(13):3901. 